\title{
CONFIANÇA, CAPITAL SOCIAL E DESENVOLVIMENTO TERRITORIAL
}

Self reliance, social capital and territorial development

\author{
Luiz Alexandre Gonçalves Cunha ${ }^{1}$
}

\begin{abstract}
RESUMO
O objetivo deste artigo é discutir algumas questões relacionadas aos conceitos de confiança e capital social e à concepção renovada de desenvolvimento denominada de desenvolvimento territorial. O interesse em relacionar aqueles conceitos com esta nova concepção surgiu a partir da análise de uma nova proposta de política pública voltada para a agricultura familiar que o atual governo brasileiro pretende implantar. Essa nova política indica que há um "sopro" renovador nas questões relacionadas ao desenvolvimento, que muito lentamente, transfere-se da universidade para os órgãos gestores das políticas públicas governamentais. No entanto, algumas questões teórico-metodológicas, que fundamentam estas novas políticas, precisam ser melhor discutidas.

Palavras-chave: confiança, capital social, território, desenvolvimento, desenvolvimento territorial.
\end{abstract}

\begin{abstract}
The aim of this article is to discuss some issues related to the concepts of self reliance and social capital and the new concept of development known as territorial development. The interest in relating these concepts to the new concept arose from the analysis of a new proposal for a national policy directed towards family agriculture, wich the present government intends to implement. This new policy suggests that there is a change affecting issues related to development, wich is gradually filtering through from universities to the organs responsible for government policy. However, some of the theoretical and methodological issues underlying these new policies need to be discussed more thoroughly.

Key-words: self reliance, social capital, development, territorial development.
\end{abstract}

${ }^{1}$ Mestre em História Econômica (UFPR) e doutorando em Desenvolvimento e Agricultura (CPDA/UFRJ). Professor Assistente da Universidade Estadual de Ponta Grossa/PR - Geografia Econômica. 


\section{INTRODUÇÃO}

O objetivo principal do artigo é discutir os conceitos de confiança e capital social, integrando-os numa concepção renovada de desenvolvimento que vem se firmando como bastante influente, a ponto de se tornar o fundamento de uma nova proposta de política pública voltada para a agricultura familiar. Trata-se da concepção de desenvolvimento territorial.

Essa nova proposta aborda a questão específica do desenvolvimento rural mais num quadro territorial do que setorial, a partir do argumento que o rural não se confunde com o agrícola. Assim, o meio rural é percebido e valorizado em quatro dimensões centrais: como espaço produtivo; espaço de residência; espaço de serviços e espaço patrimonial.

A proposta foi divulgada no documento "Agricultura familiar, reforma agrária e desenvolvimento local para um novo mundo rural: política de desenvolvimento rural com base na expansão da agricultura familiar e sua inserção no mercado". O documento é de 16/03/99 e institucionalmente emana do INCRA que se vincula ao Ministério da Política Fundiária e da Secretaria de Desenvolvimento Rural-SDR do Ministério da Agricultura.

Não é um dos objetivos deste artigo analisar esta proposta de política pública, mas sim utilizá-la como fonte de inspiração na tentativa que se faz neste artigo de integrar os conceitos e a concepção já citados.

\section{CONFIANÇA E CAPITAL SOCIAL}

O conceito de confiança está sendo amplamente considerado nas discussões sobre o desenvolvimento, muito embora ele esteja presente em abordagens que têm outras preocupações. É o que se pode constatar na obra de Anthony GIDDENS (1991), na qual o conceito de confiança aparece como um dos fundamentos da sua formulação teórica que visa "...tentar obter uma nova caracterização tanto da natureza da modernidade quanto da ordem pós-moderna que deve emergir do outro lado da era atual" (GIDDENS, 1991, p. 13). Nesses termos, Giddens trabalha na formatação de uma teoria social crítica que dê conta da sociedade contemporânea.

Numa visão derivada de Giddens, mas bem menos abrangente, o conceito de confiança é, geralmente, definido a partir de suas relações 
estreitas com o conceito de capital social. Dessa forma, Francis FUKUYAMA (1996), inspirado em James COLEMAN (1990), o pioneiro na utilização do conceito de capital social, define este tipo de capital, como sendo "... a capacidade de as pessoas trabalharem em conjunto, em grupos e organizações que constituem a sociedade civil, para a prossecução de causas comuns" (FUKUYAMA, 1996, p. 21-22). A questão central é a capacidade de associação dos membros das diversas sociedades e comunidades, algo que "... depende do grau de partilha de normas e valores no seio de comunidades e da capacidade destas para subordinarem os interesses individuais aos interesses mais latos dos grupos" (FUKUYAMA, 1996, p. 22). Ou seja, depende fundamentalmente do grau de confiança dos membros de uma comunidade entre si. Nesses termos, pode-se afirmar que "a confiança nasce desta partilha de valores e tem, como veremos, um vasto e mensurável valor econômico" (FUKUYAMA, 1996, p. 22).

Robert D. PUTNAM (1996) considera que confiança é um componente básico do capital social-CS. Básico, mas não único, tendo em vista que identifica também "...outras formas de capital social, como as normas e as cadeias de relações sociais" (PUTNAM, 1996, p. 179180). Mas é inegável que para Putnam a confiança é o ponto fundamental. É, sem dúvida, na análise das fontes de confiança que gira seu estudo sobre a Itália, no qual Putnam procurou analisar como uma mudança institucional (implantação dos governos regionais) influenciou as duas grandes regiões italianas, em termos de desenvolvimento: o norte "desenvolvido" e o sul "subdesenvolvido". A conclusão é que os efeitos foram muito mais positivos no norte do que no sul, indicando que a herança cultural é o fator fundamental na determinação dos níveis de desenvolvimento de uma região ou de um país. Em outras palavras, o norte da Itália apresenta um nível de capital social herdado mais elevado do que o sul e isso são suficientes para explicar as diferenças de desenvolvimento e, mais especificamente, o impacto que as políticas, projetos e reformas possam vir a ter numa determinada região.

Da mesma forma, a perspectiva histórica não está ausente em Giddens, que se preocupa com a evolução dos "ambientes de confiança e risco nas culturas pré-modernas e modernas", mostrando a historicidade presente nestes ambientes. Para ele, nas culturas prémodernas a confiança é excessivamente localizada e nos ambientes de confiança, as questões fundamentais são as relações de parentesco, a comunidade local, as cosmologias religiosas e a tradição. Enquanto que, na cultura moderna, os ambientes de confiança têm como contexto 
geral os sistemas abstratos desencaixados. Destacam-se, especificamente, as relações pessoais, estes sistemas abstratos e o pensamento contrafactual orientado para o futuro (GIDDENS, 1991, p. 104).

A análise de Giddens centra-se nos "ambientes de confiança e risco" característicos da sociedade contemporânea, o que o leva a concluir que "a confiança pode ser definida como crença na credibilidade de uma pessoa ou sistema, tendo em vista um dado conjunto de resultados ou eventos em que essa crença expressa uma fé na probidade ou amor de um outro, ou na correção de princípios abstratos (conhecimento técnico)" (GIDDENS, 1991, p. 41).

A análise de Giddens não prioriza as relações entre confiança e desenvolvimento. Neste artigo é esta relação que importa. Para abordála é indispensável recorrer-se ao conceito de capital social. Dessa forma, no trabalho de Putnam a relação entre confiança e desenvolvimento é apenas aventada, na medida em que ele não faz referência a esta relação, mas utiliza o conceito de CS. Ao contrário, em Francis FUKUYAMA (1996) a relação entre confiança e desenvolvimento é central, tendo em vista que ele procura mostrar que "uma das lições mais importantes que podemos extrair de uma observação da vida econômica é a de que bem-estar de uma nação, bem como a sua capacidade de competir, são condicionados por uma única e subtil característica cultural: o nível de confiança inerente à sociedade em causa" (FUKUYAMA, 1996, p. 19).

Essa conclusão fundamenta-se na tese de que a confiança é o componente mais importante do CS, assim como em Putnam. É o que fica evidente na afirmação que "o capital social, por seu turno, é uma capacidade social cuja emergência se deve à prevalência do factor confiança numa dada sociedade ou em parte dela. Pode corporizar-se no grupo social mais pequeno e mais básico, como a nação, bem como em todos os grupos intermediários" (FUKUYAMA, 1996, p. 37). A partir desta conclusão Fukuyama empreende, no livro citado, um estudo comparativo envolvendo diversos países, vistos como diferentes culturas, procurando caracterizá-las pelos níveis de capital social e destarte de confiança. Fukuyama propõe algumas generalizações como a que classifica os países considerados na análise em dois tipos básicos: as sociedades familiaristas (China e Itália); e as não-familiaristas (Alemanha e Japão). Nos primeiros haveria um baixo índice de CS, enquanto que nos últimos o mesmo índice é bem maior, tudo isto com reflexos na economia, respectivamente, negativos e positivos (FUKUYAMA, 1996, p. 28). Ou seja, para Fukuyama o desempenho 
econômico é um problema que "...reside no déficit [ou não] de algo a que o sociólogo James Coleman chamou de capital social” (FUKUYAMA, 1996, p. 21-22).

Para esclarecer ainda mais esta questão recorre-se a Jawdat ABU-EL-HAJ (1999) quando ela afirma que, segundo o pensamento de James COLEMAN (1990), “...existe uma complementação entre capital físico-econômico (insumos, infra-estrutura e financiamento), capital humano (educação e preparação técnica) e capital social (relações de confiança)" (ABU-EL-HAJ, 1999, p. 68).

Procurando comentar a relação entre estes diferentes tipos de capital Abu-el-Haj afirma ainda que:

A otimização do capital físico-econômico e do capital humano é alcançada na medida em que as relações de confiança e reciprocidade aumentam na comunidade. Em outras palavras, em duas ou mais comunidades em que o nível educacional das pessoas e os recursos materiais oferecidos são constantes, o que distingue o desempenho de seus membros é a confiança estabelecida, que permite mobilização coletiva e maximização dos recursos individuais existentes. A capacidade de ação é ampliada em situações em que a confiança permeia uma coletividade (ou associação), facilitando a otimização do uso de recursos sócio-econômicos e humanos disponíveis (ABU-EL-HAJ, 1999, p. 68).

Nesses termos, a relação entre confiança e CS com a questão do desenvolvimento territorial parece bastante evidente, pelo menos no que se refere às possibilidades de uma dimensão territorial do desenvolvimento fazer-se presente. Isso porque, considerando os diferentes índices de CS encontrados em distintos territórios, as possibilidades de desenvolvimento também seriam diversas. Em outras palavras, um território com baixo índice de CS é um "ator" primevo e seminal sofrível, não sendo capaz de induzir o processo de desenvolvimento com a mesma eficiência de um território no qual o índice de CS seja elevado. No entanto, a questão não é tão simples assim. São, justamente, as complexidades envolvidas nesta relação que se procura abordar na próxima parte deste artigo. 


\section{CAPITAL SOCIAL E DESENVOLVIMENTO TERRITORIAL}

Para destacar as complexidades envolvidas na relação em tela é preciso chamar atenção para uma primeira questão que pode ser resumida da seguinte forma: como se pode criar CS nos territórios ou regiões nas quais o índice de CS é baixo? Na verdade, essa questão depende de uma outra que significa desvelar as formas de como se adquire, forma-se e se transmite CS no tempo e no espaço. As complexidades, em parte, relacionam-se com estas questões, e é sobre elas também que parecem residir as principais divergências e controvérsias, sendo identificável “...uma polarização teórica entre duas abordagens interpretativas do capital social: o culturalismo e o neoinstitucionalismo" (ABU-EL-HAJ, 1999, p. 72).

O que se defende é que a análise destas divergências e controvérsias permite levantar novas questões relacionadas à concepção de desenvolvimento territorial, concepção essa que não é considerada pelos autores envolvidos na discussão analisada a seguir. É esse argumento que se tenta comprovar após a análise, que se baseia no trabalho de Jawdat Abu-el-Haj, o qual defende que na vertente culturalista destaca-se o trabalho de Robert Putnam, enquanto que, na neo-institucionalista, os destaques ficam por conta dos trabalhos de Peter EVANS (1996, 1992) e Jonathan FOX (1996).

Para Abu-el-Haj as grandes conclusões de Putnam que corroboram o seu culturalismo são que a especificidade cultural é a chave para se explicar o nível de CS e o "predomínio do elemento cultural no grau de avanço do associativismo horizontal e a complementação de ações junto às instituições públicas" (ABU-EL-HAJ, 1999, p. 70). É importante lembrar que são conclusões que se referem ao seu estudo sobre a Itália. Segundo ainda Abu-el-Haj, no pólo neo-institucional, liderado por Evans e Fox, rejeita-se as conclusões culturalistas, defendendo-se "...que a ausência de horizontalidade social [ou CS], na grande maioria dos países em desenvolvimento [ou regiões/territórios subdesenvolvidos], é fruto de ações políticas preteridas pelos regimes autoritários" (ABU-EL-HAJ, 1999, p. 71).

Dessa forma, "Evans e Fox assumem o pressuposto básico de que as instituições públicas têm, além do monopólio da coerção, a exclusividade da mobilização dos recursos sociais" (ABU-EL-HAJ, 1999, p. 71). Pode-se concluir, a partir desta argumentação, que a criação ou elevação do índice de CS em determinados territórios dependeria da intervenção do Estado, já que o "Estado na sociedade moderna é a arena principal da convergência das demandas sociais, determinando, 
em última instância, o sucesso das iniciativas voluntárias. [...] O poder de intervenção social determina o sentido do espaço público. As instituições, nessa visão, forjam os rumos da ação coletiva aniquilando sua capacidade de ação" (ABU-EL-HAJ, 1999, p. 71-72). Ainda segundo Abu-el-Haj, os neo-institucionalistas, com destaque para Evans, passaram a defender o Estado como tendo uma função de "...ação reguladora da interação social para um ativismo político mobilizador do capital social [...] o ativismo institucional incentiva às redes cívicas adormecidas ou historicamente reprimidas a ganharem uma vida autônoma" (ABU-EL-HAJ, 1999, p. 72). Trata-se de um não categórico a qualquer determinismo cultural em matéria de mudança social, ou no que interessa neste artigo, em termos de processos de desenvolvimento.

Numa posição aparentemente intermediária ou contraditória entre os dois pólos analisados parece estar Francis Fukuyama. Isso porque, num determinado momento, afirma que "o capital social difere dos outros tipos de capital humano até hoje conhecidos porque é habitualmente criado e transmitido através de mecanismos culturais, como a religião, a tradição ou o hábito historicamente transmitido" (FUKUYAMA, 1999, p. 37), colocação que o remete ao culturalismo de Putnam. Porém, em outro momento, Fukuyama afirma que "nos casos em que existe um défice em capital social, essa carência pode ser suprida através da intervenção estatal, tal como o Estado pode rectificar um défice em capital humano através da construção de mais escolas e universidades" (FUKUYAMA, 1996, p. 28), revelando uma "veia" neo-institucionalista de grosso calibre. Na verdade, é a diversidade socioterritorial que o leva a relativizar suas conclusões, assim como parece ter ocorrido com Putnam, conforme notou Abu-el-Haj, ao afirmar que Putnam, na sua última pesquisa sobre o declínio do capital social americano, teria recuado de seu "excessivo determinismo cultural" (ABU-EL-HAJ, 1999, p. 70).

Algum recuo dos neo-institucionalistas parece que também é necessário, ao se tomar conhecimento da crítica feita a eles por Abuel-Haj, quando afirma que "assim como o culturalismo, as críticas neoinstitucionais sucumbem ao excessivo determinismo". E arremata defendendo que:

...a imoderada obsessão dos neo-institucionalistas pelo desempenho institucional obscurece as condições políticas subjacentes à institucionalização [...]. A abordagem neo-institucional omite um fator fundamental subjacente ao ativismo institucional: a natureza das elites políticas e seu projeto de poder [...] as burocracias governamentais, 
por mais efetivas e preparadas que sejam, autonomamente não teriam o poder político necessário para conduzir isoladamente as políticas públicas. (ABU-EL-HAJ, 1999, p. 77)

Partindo-se da premissa de que o "ativismo institucional", tal qual é defendido pelos neo-institucionalistas, só pode ser desencadeado por um poder central de caráter estatal, necessariamente trabalha-se com a perspectiva territorial seja numa escala local, regional ou nacional, conforme a definição de Marcelo Lopes de SOUZA (1995) quando afirma que território "é fundamentalmente um espaço definido e delimitado por e a partir de relações de poder" (SOUZA, 1995, p. 78).

Essa definição baseia-se num conceito de território que mantém aspectos da abordagem clássica deste conceito, como espaço delimitado política e juridicamente por uma estrutura de poder, que determina as relações de domínio, controle e gestão que caracterizam o território. No entanto, o conceito de território não se aplica apenas aos seus respectivos Estados nacionais e sua divisões administrativas (estados e municípios). Ou seja, não se trata, exclusivamente, de regiões controladas por um determinado nível de poder estatal, mas também aquelas frações do espaço geográfico que são fortemente influenciadas por grandes empresas, as quais, em alguns casos, são as instituições decisivas na gestão de um determinado território. Manuel Correia de ANDRADE (1994) resumiu esta questão da seguinte forma: "deve-se ligar sempre a idéia de território à idéia de poder, quer se faça referência ao poder público, estatal, quer ao poder das grandes empresas que estendem os seus tentáculos por grandes áreas territoriais, ignorando as fronteiras políticas" (ANDRADE, 1994, p. 213).

$\mathrm{Na}$ verdade, esta é apenas uma das vertentes básicas das "abordagens conceituais de território", segundo Rogério HAESBAERT e Éster LIMONAD(1999), os quais a denominam de vertente jurídicopolítica. Além dessa, há também as vertentes culturalista e econômica (HAESBAERT; LIMONAD, 1999, p. 12).

No âmbito deste artigo, o que importa perceber é que a vertente jurídico-política permite fundamentar a concepção de desenvolvimento territorial de uma forma que não se desconsidere "as condições políticas subjacentes à institucionalização", e também "a natureza das elites políticas e seus projetos de poder [...]", conforme a crítica de Abu-elHaj os neo-instucionalistas. Em outras palavras, um conceito de território centrado na questão do poder permite dar consistência a concepção de desenvolvimento territorial, a partir da conclusão de que políticas públicas de caráter territorial não podem ser formuladas e 
implementadas sem a participação dos atores públicos e privados vinculados ao maior número possível de segmentos econômicos, sociais, políticos e culturais, os quais estão presentes em diferentes configurações regionais ou territoriais. Dessa forma, modelos e projetos de desenvolvimento territorial dependem basicamente de uma "engenharia política" que promova um "governança" ou um "pacto" que envolva a maior diversidade possível de atores. Ricardo ABRAMOVAY (1998) afirma que "projetos de desenvolvimento terão tanto mais chances de sucesso quanto mais forem capazes de extrapolar um único setor profissional". Isso porque, o desenvolvimento territorial "apóia-se, antes de tudo, na formação de uma rede de atores trabalhando para a valorização dos atributos de uma certa região" (ABRAMOVAY, 1998, p. 13).

Dessa forma, é preciso mudar as formas de encaminhamento das questões institucionais, regulacionais e propriamente políticas. $O$ fundamental é perceber que uma consideração com o "político" pode ser decisiva para superar os determinismos culturais e institucionais presentes nas abordagens desenvolvimentistas fundamentadas nos conceitos de confiança e capital social, facilitando a integração destes conceitos com a concepção de desenvolvimento territorial. E não se pode perder de vista, como afirma FUKUYAMA (1996, p. 48), que, "freqüentemente, o que começa como um acto político termina corporizado num atributo cultural".

Trabalhar com um conceito de território definido e considerado pela via das relações de poder e, destarte, políticas, não significa uma falta de reconhecimento da importância das outras vertentes que também consideram este conceito. Na verdade, a opção política devese a um preocupação com a questão do desenvolvimento, que, por sua vez, pressupõe a formulação e implementação de projetos, planos e políticas públicas, que tenham como objetivos transformar ou dinamizar comunidades específicas. Principalmente quando se tratam de propostas abertas, nas quais estejam presentes um certo grau de descentralização, numa tentativa de integrar participativamente a comunidade local. Nesses termos é que se acredita que ganha relevância a questão das relações de poder, as quais passam pela atuação de grupos, classes e instituições, enfim, atores individuais e coletivos, públicos e privados, que atuam a partir de heranças culturais, políticas e econômicas relativas a uma determinada região, vista, no caso, como um território.

No entanto, não se deve deixar de considerar uma certa preocupação de John WILKINSON (1997) com uma excessiva 
"politização da economia", presentes nas pesquisas e trabalhos sobre a agricultura familiar centrados nas questões de poder e "relações de força", abordagens estas que se recusam "em considerar temas relacionados com a eficiência produtiva" (WILKINSON, 1997, p. 26). Para ele, "a atividade econômica se integra aos processos sociais, embora as opções estejam longe de serem ilimitadas" (WILKINSON, 1997, p. 48). Ou seja, como as opções econômicas não são "ilimitadas", há um espaço para análises especificamente técnico-produtivas, assim como há também para análises que priorizem questões culturais. Por isso, é que se vem fazendo a defesa de concepções de desenvolvimento que contemplam a dimensão espacial (CUNHA, 1998), pois se acredita que estas dimensão pode permitir uma consideração especial com as diversidades e a simultaneidade dos processos socioespaciais.

\section{CONCLUSÃO}

A relação entre os conceitos de confiança e capital social e a concepção de desenvolvimento territorial é imediata a partir da constatação de que os níveis de confiança e capital social variam em termos espaciais, conforme a diversidade regional e territorial existente. Assim como, é fácil constatar também, que a diversidade regional e territorial, por outro lado, influenciam nos níveis e criação de confiança e capital social nas diferentes comunidades. Isso é importante mas não é suficiente, se o propósito do pesquisador ou planejador é o desenvolvimento de uma comunidade e de seu território. Nesse caso, a questão torna-se mais complexa, tendo em vista que nos processos de desenvolvimento afloram interesses divergentes entre os diferentes atores individuais e coletivos que atuam num determinado território, os quais têm diversas e conflitantes percepções da realidade.

Assim, procurou-se abordar a complexidade da relação analisada, indicando que o conceito de território definido a partir das relações de poder, domínio, controle e gestão próprias de territórios específicos, pode ser importante para dar consistência teórico-metodológica à relação entre os conceitos de confiança e capital social e a concepção de desenvolvimento territorial, quando a preocupação é com a formulação e implementação de projetos, planos e políticas públicas que visam transformar e dinamizar determinadas comunidades. 


\section{REFERÊNCIAS}

ABRAMOVAY, R. O capital social dos territórios: repensando o desenvolvimento rural. Fortaleza: MEPF / Governo do Ceará, 1998. 18p. (Seminário sobre Reforma Agrária e Desenvolvimento Sustentável) (abramovay@usp.br).

ABU-EL-HAJ, J. O debate em torno do capital social: uma revisão crítica. Revista Brasileira de Informação Bibliográfica em Ciências Sociais BIB, Rio de Janeiro, n. 47, p. 65-79, 1. sem. 1999.

ANDRADE, M. C. Territorialidades, desterritorialidades, novas territorialidades: os limites do poder nacional e do poder local. SANTOS, M.; SOUZA, M. A. A.; SILVEIRA, M. L. (Orgs). Território: globalização e fragmentação. São Paulo: Hucitec-ANPUR, 1994. p. 213-220.

COLEMAN, J. The foundations of social theory. Cambridge: Harvard University Press, 1990.

CUNHA, L. A. G. Por um projeto sócio-espacial de desenvolvimento. Revista de História Regional, Ponta Grossa, v. 3, n. 2, p. 91-114, inverno 1998. (www. uepg.br).

EVANS, P. Government action, social capital and development: reviewing the evidence on synergy. World development, v. 24, n. 6, p. 1119-1132, 1996.

EVANS, P. O Estado como problema e solução. Lua Nova: revista de cultura e política, Rio de Janeiro, n. 28/29, p. 107-156, 1993.

FOX, J. How does civil society thicken? The political construction of social capital in rural. World development, Mexico, v. 24, n. 6, p. 10891103, 1996.

FUKUYAMA, F. Confiança: valores sociais e criação de prosperidade. Lisboa: Gradiva, 1996. 412 p.

GIDDENS, A. As conseqüências da modernidade. São Paulo: Unesp, 1991. $177 \mathrm{p}$. 
HAESBAERT, R.; LIMONAD, E. O território em tempos de globalização. GEO UERJ, Rio de Janeiro, n. 5, p. 7-19, 1. sem. 1999.

PUTNAN, R. D. Comunidade e democracia: a experiência da Itália moderna. Rio de Janeiro: FGV, 1996.

SOUZA, M. L. O território: sobre espaço e poder, autonomia e desenvolvimento. In: CASTRO, I. E.; GOMES, P. C.; CORREAA, R. L. (Orgs). Geografia: conceitos e temas. Rio de Janeiro: Bertrand Brasil, 1995. p. 77-116.

WILKINSON, J. Mercosul e produção familiar: abordagens teóricas e estratégias alternativas. Estudos sociedade e agricultura, Rio de Janeiro, n. 8, p. 25-49, abr. 1997. 